\title{
PENGARUH PENERAPAN STRATEGI PELAKSANAAN 1 PADA KLIEN PERILAKU KEKERASAN TERHADAP MENGONTROL MARAH
}

\author{
Novita Anggraini ${ }^{1}$, Gyatri F $^{2}$ \\ ${ }^{1,2}$ Program Studi Ilmu Keperawatan Universitas Katolik Musi Charitas Palembang \\ Jl.Kol.H. Burlian Km.7 Palembang \\ Email : novitaanggraini06@gmail.com
}

\begin{abstract}
Abstrak
Kesehatan jiwa suatu keadaan yang memungkinkan perkembangan fisik, intelektual, dan emosional yang optimal dari seseorang dan perkembangan itu selaras dengan keadaan orang lain. Diperkirakan penduduk Indonesia yang menderta gangguan jiwa sebesar 25\%. Seseorang yang menderita skizofrenia dan mempunyai gejala perilaku kekerasan harus mendapat penanganan atau tindakan keperawatan yang tepat. Penelitian ini bertujuan memperoleh informasi tentang pengaruh penerapan asuhan keperawatan pada klien dengan perilaku kekerasan di ruang rawat inap Bangau RS Ernaldi Bahar Palembang. Penelitian ini dilakukan dengan menggunakan desain penelitian kuantitatif dengan desain pra experimental dengan menggunakan rancangan one group pre-test dan post-test. Sampel yang diperoleh sebanyak 50 responden dengan teknik purposive sampling. Dari hasil uji statistik yang dilakukan, didapatkan bahwa mean rank mengontrol marah sebelum di berikan strategi pelaksanaan 1 adalah 23,23 dan sesudah 10,00. Hasil uji menggunakan wilcoxon di dapatkan nilai $p$ value $=0,000<(0,05)$ yang artinya hipotesis Ha ada pengaruh terhadap penerapan strategi pelaksanaan 1 sebelum dan sesudah pada klien perilaku kekerasan terhadap mengontrol marah di unit rawat inap Bangau Rumah sakit Ernaldi Bahar Palembang.
\end{abstract}

Kata Kunci: Perilaku kekerasan, Strategi pelaksanaan, Asuhan keperawatan

\begin{abstract}
Sanity is a condition which enables optimal development of physical, intellectual and emotional to be in tune with others' condition. It is estimated that $25 \%$ of Indonesia citizen experience psychoneurotic. Schizophrenia has definite violence attitude and it requires certain treatment and care. This study aims to obtain information about the influence of strategy implementation for violence performer toward the ability to control anger in Bangau Inpatient unit Ernaldi Bahar Palembang. This study implemented the qualitative research design namely pre-experimental design by using one group pre-test post-test. The sample are 50 respondents which was selected by using purposive sampling method. From the results of statistical tests performed, it was found that the mean rank given to control angry before implementation strategy 1 was 23.23 and after 10.00. The test results using Wilcoxon in getting $p$ value $=0.000<(0.05)$ which means that the hypothesis $\mathrm{Ha}$ no effect on the implementation of strategies for implementation 1 before and after the client's violent behavior towards controlling angry at inpatient units Stork hospital Ernaldi Bahar Palembang .
\end{abstract}

Keywords: Voilence attitude, strategy implementation, nursing care, sanity, teraupetik communication, nurse role. 


\section{PENDAHULUAN}

Kesehatan jiwa merupakan keadaan perkembangan fisik, intelektual, dan emosional yang optimal dari seseorang dan perkembangan itu selaras dengan keadaan orang lain (UU No.3 Tahun 1996 dalam Nasir, 2011). Kesehatan jiwa adalah terbebas dari gangguan jiwa, namun juga suatu hal yang dibutuhkan setiap orang (Depkes, 2005).

Gangguan jiwa adalah suatu sindrom, pola psikologis, perilaku yang secara klinis yang terjadi pada seseorang yang dikaitkan dengan adanya distres (misalnya: Gejala nyeri) atau disabilitas (kerusakan pada satu atau lebih daerah fungsi yang penting) atau disertai peningkatan risiko kematian yang menyakitkan, nyeri, disabilitas dan sangat kehilangan kebebasan (American Psychiatric Associaton, 1994 dalam Videbeck, 2012). Selain itu, Gangguan jiwa juga didefinisikan sebagai suatu kondisi adanya gangguan pada fungsi kejiwaan. Fungsi kejiwaan meliputi: proses berpikir, emosi, kemauan, dan perilaku psikomotorik, termasuk bicara (Undang-Undang No.3 Tahun 1996 dalam Nasir dkk, 2011).

Di Amerika Serikat, menggambarkan hampir tiga juta penduduk yang sedang, telah, atau akan terkena skizofrenia. (Videbeck, 2008).

Gangguan jiwa merupakan gejala atau perubahan perilaku, serta dapat menimbulkan penderitaan dan hambatan dalam menjalankan fungsi sebagai manusia (UU No.18, 2014)

Berdasarkan Riset Kesehatan Dasar (Riskesdas) 2013, prevalensi gangguan jiwa di provinsi Aceh 2,7 permil, Sumatera Utara 0,9 permil, Sumatera Barat 1,9 permil, Riau 0,9 permil, Jambi 0,9 permil, Sumatera Selatan 1,1 permil, Bengkulu 1,9 permil, Lampung 0,8 permil serta yang paling rendah yaitu provinsi Kalimantan Barat 0,7 permil.

Gangguan jiwa yang banyak terjadi pada seseorang adalah gangguan jiwa skizofrenia, dimana terdapat $10 \%$ orang dewasa mengalami skizofrenia saat ini dan $25 \%$ penduduk diperkirakan akan mengalami gangguan jiwa pada usia tertentu (Wakhid, 2013). Prevalensi skizofrenia diperkirakan sekitar $1 \%$ dari seluruh penduduk.

Gangguan jiwa yang menjadi penyebab penderita di bawa ke rumah sakit adalah salah satunya perilaku kekerasan. Perilaku kekerasan adalah prilaku individu untuk melukai maupun mencelakakan orang lain (Purba, 2008). Syahrial (2011) dalam Nuraendah (2012) menemukan bahwa $46 \%$ penderita skizofrenia melakukan kekerasan. DepKes RI, 2010, menyatakan jumlah penderita gangguan jiwa di Indonesia mencapai 2,5 juta diperkirakan sekitar $60 \%$ menderita resiko perilaku kekerasan di Indonesia (Wirnata, 2012). 
Menurut rekam medis Rumah Sakit Ernaldi Bahar Palembang mencatat jumlah pasien gangguan jiwa rawat inap dengan perilaku kekerasan pada tahun 2013 sejumlah 1812 klien, pada tahun 2014 terjadi peningkatan yaitu 1844 klien, dan pada tahun 2015 terjadi penurunan sejumlah 1432 klien, sedangkan data pada bulan november 2015 yaitu 114 klien, terjadi penurunan pada bulan Desember 2015 yaitu 100 klien, sedangkan dibulan Januari 2016 terjadi peningkatan yaitu sejumlah 102 klien.

Berdasarkan data diatas pasien rawat inap yang menderita gangguan jiwa perilaku kekerasan pada tiga tahun terakhir dan tiga bulan terakhir ini menunjukkan kecenderungan terjadi peningkatan, maka dari itu klien dengan perilaku kekerasan perlu diberikan tindakan strategi pelaksanaan agar klien mampu mengontrol marah.

Perawat merupakan tenaga kesehatan yang lebih banyak menghabiskan waktu dengan pasien rawat inap dibandingkan dengan profesi kesehatan jiwa lain, sehingga perawat yang bekerja 24 jam lebih terlibat dalam pencegahan dan penangan perilaku amuk dan lebih beresiko menjadi korban terhadap perilaku kekerasan oleh klien.

Klien perilaku kekerasan merupakan diagnosa yang memiliki resiko lebih tinggi, jika klien kambuh dapat membahayakan diri sendiri, orang lain, dan lingkungan. Maka dari itu untuk mencegah agar tidak terjadi hal tersebut maka perawat harus melakukan, intervensi keperawatan dengan menerapkan setrategi pelaksanaan pada pasien perilaku kekerasan. Strategi pelaksananan adalah panduan seorang perawat jiwa ketika berinteraksi dengan klien (Fitria, 2012). Dan dengan strategi pelaksanaan perawat dapat membantu pasien untuk mengenali penyebab, tanda dan gejala serta cara mengontrol marah yang dilakukan

Berdasarkan studi pendahuluan yang peneliti lakukan pada bulan Februari, dilakukan wawancara singkat terhadap lima klien perilaku kekerasan, empat diantara lima klien peneliti menanyakan apa penyebab bapak marah sedangkan klien menjawab hanya dengan tertawa tidak ada kesingkronan atau jawaban menyimpang dari pertanyaan yang diberikan, sedangkan satu diantara lima klien sudah mengetahui tanda dan gejala serta cara mengontrol marah yang dilakukan. klien menceritakan bahwa saat itu kondisi wajahnya memerah, tangan mengepal dan ia secara tidak langsung sudah mencoba untuk menarik nafas dalam dalam ketika rasa itu timbul.

Berdasarkan uraian diatas peneliti tertarik melakukan penelitian tentang Pengaruh Penerapan Strategi Pelaksanaan 1 pada Klien Perilaku Kekerasan terhadap Mengontrol Marah di unit rawat inap Bangau Rumah Sakit Ernaldi Bahar Palembang. 


\section{METODE PENELITIAN}

Metode yang digunakan dalam penelitian ini adalah pra eksperimen dengan rancangan penelitian one group pretest posttest. Penelitian ini dilaksanakan di Unit Bangau RS Ernaldi Bahar Palembang.

Populasi dalam penelitian ini adalah semua perilaku kekerasan yang ada di unit Banagau sebanyak 53 orang sedangkan tehknik pengambilan sampel dalam penelitian ini menggunakan metode purposive sampling didapat sampel sebanyak 50 responden.

Tehnik pengumpulan data yang digunakan adalah data primer. Data yang diperoleh peneliti melalui

Pemberian kuesioner. Peneliti memberikan pre test terlebih dahulu berupa kuesioner kemudian memberikan intervensi strategi pelaksanaan 1 dan memberikan post test kuesioner kembali.

\section{HASIL DAN PEMBAHASAN}

1. Mengontrol Marah Sebelum Dilakukan Strategi Pelaksanaan.

\begin{tabular}{lllll}
\hline Variabel & Median & n & SD & -Max \\
\hline $\begin{array}{l}\text { Mengontrol } \\
\text { marah } \\
\text { sebelum SP 1 }\end{array}$ & & 50,00 & 4 & $68-72$ \\
\end{tabular}

Dari hasil penelitian diperoleh hasil

nilai median dari mengontrol marah sebelum dilakukan strategi pelaksanaan 1 adalah 69,00, standar deviasi 1,444 dan minimum 68, maximum 72 . banyaknya klien yang sudah mampu mengontrol marah dikarenakan pada ruang rawat inap tersebut telah diadakan program strategi pelaksanaan dalam satu minggu diadakan dua kali, program tersebut ditujukkan oleh perawat untuk klien, perawat mengajarkan kepada klien yaitu dengan cara tarik nafas, tarik dari hidung, tahan dan tiup melalui mulut dilakukan 5 kali saat merasakan marah dan jika klien belum mampu mengontrol amarahnya perawat mengajarkan klien untuk memukul bantal atau kasur dan juga di ruangan telah tertempel poster yang berkaitan dengan cara mengontrol marah poster tersebut berisi cara cara mengontrol marah yaitu latihan nafas dalam dan memukul bantal atau kasur. Poster tersebut tertempel di satu ruangan pertemuan ditempat biasanya perawat melakukan strategi pelaksanaan untuk klien dan poster tersebut sering dibaca oleh klien. Hal inilah yang membuat klien sedikit banyaknya mengerti bagaimana cara mengontrol marah.

2. Mengontrol Marah Setelah Dilakukan Strategi Pelaksanaan 1.

\begin{tabular}{|c|c|c|c|c|c|c|}
\hline variabel & Mean & $\mathrm{N}$ & SD & $\begin{array}{l}\text { Min- } \\
\max \end{array}$ & $95 \%$ & \\
\hline & & & & & Lower & upper \\
\hline $\begin{array}{l}\text { Mengontrol } \\
\text { marah } \\
\text { sesudah SP } \\
1\end{array}$ & 71,00 & 50 & 0,808 & $70-72$ & 70,77 & 71,23 \\
\hline
\end{tabular}

Dari hasil penelitian diperoleh hasil nilai rata-rata mengontrol marah sebelum dilakukan strategi pelaksanaan 1 adalah 
71,00, standar deviasi 0,808 dan minimum 70, maximum 72. Dari hasil estimasi interval dapat disimpulkan $95 \%$ yang diyakini bahwa rata-rata mengontrol marah adalah Lower 70,77 dan Upper 71,23. Bahwa disini tidak berbeda pada sesudah dilakukan strataegi pelaksanaan 1 pada mengontrol marah dalam kategori baik sama juga dengan sebelum dilakukan strategi pelaksanaan 1 pada mengontrol marah, tetapi jumlah responden pada sesudah itu dapat mengontrol marahnya lebih banyak atau meningkat dibandingkan dengan jumlah responden sebelum dilakukan strategi pelaksanaan 1 pada mengontrol marah. Cara mengontrol marah tanpa melukai diri sendiri ataupun orang lain dengan cara menraik menarik nafas dalam, banyak dari klien tersebut yang mau mengikuti dan meragakan apa yang telah diajarkan oleh perawat, dan perawat selalu mengingatkan pada klien untuk sering melatih diri tentang cara mengontrol marah yang sudah diajarkan. Pada saat peneliti melakukan strategi pelaksanaan 1 terlebih dahulu peneliti memperkenalkan diri menjelaskan apa yang akan perawat lakukan hal ini membuat klien merasa nyaman sehingga klien merespon baik dan menjawab semua pertanyaan yang diberikan, mendengarkan dan menjawab apa yang ditanyakan peneliti dan mampu mengulang serta memperaktekkan apa yang peneliti ajarkan. Dan ini berdampak baik dimana pada saat klien akan mengalami perilaku kekerasan klien tersebut akan melakukan cara mengontrol marah seperti yang sudah diajarkan oleh perawat saat memberikan stategi pelaksanaan 1 .

3. Pengaruh antara sebelum dan sesudah dilakukan intervensi keperawatan di lakukan dengan strategi pelaksanaan 1 .

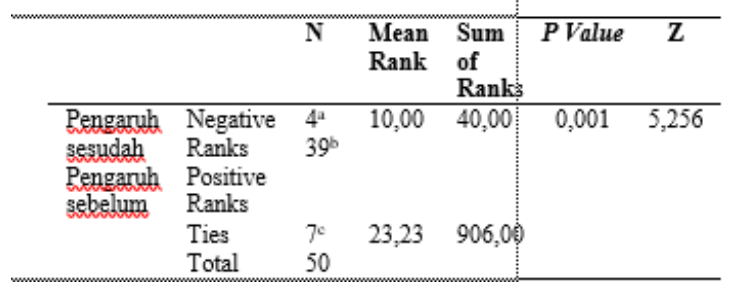

Dapat dilihat bahwa setelah diberikan strategi pelaksanaan 1 sebanyak 4 responden memiliki pengaruh kearah yang negative, 39 responden memiliki pengaruh kearah positive, sedangkan responden yang memiliki pengaruh tetap sebelum dan sesudah dilakukan strategi pelaksanan 1 sebanyak 7 responden. Mean rank mengontrol marah sebelum strategi pelaksanaan 1 adalah 23,23, sedangkan meank rank mengontrol marah sesudah startegi pelaksanaan 1 adalah 10,00. Dengan hasil uji statistik didapatkan 0,000 dengan taraf signifikan $\alpha=0,05$ yang artinya $0,000<$ 0,05, maka dapat disimpulkan bahwa Ho ditolak dan Ha diterima, yang artinya ada perbedaan yang signifikan mengontrol marah sebelum dan sesudah strategi pelaksanaan 1 dan ada pengaruh penerapan strategi pelaksanaan pada klien perilaku kekerasan terhadap mengontrol marah di unit rawat inap 
Bangau Rumah sakit Ernaldi Bahar Palembang.

Bahwa ada pengaruh strategi pelaksanaan 1 terhadap kemampuan klien dalam mengontrol marah, banyaknya klien yang mampu marah dikarenakan didalam ruangan tersebut sering dilakukan program strategi pelaksanaan 1 setiap dua kali dalam seminggu, didalam ruangan tersebut terdapat banyak poster untuk mengontrol marah, selain hal tersebut dari hasil observasi peneliti melihat klien sering menarik nafas dalam saat terdapat tanda-tanda marah atau kesal, selain hal tersebut klien tampak memukul bantal saat akan marah. Di dukung juga teori yang menyatakan bahwa apabila mengontrol marah dengan teknik menarik nafas dalam maka Oksigen masuk ke dalam paru-paru lalu oksigen dibawa oleh darah menuju otak kemudian dapat meningkatkan jumlah oksigen ke otak lalu dapat mengembalikan keseimbangan mental dan emosional maka tubuh akan menjadi rileks. Sehingga apabila klien mengalami tandatanda akan perilaku kekerasan maka teknik yang dapat dilakukan dengan menarik nafas dalam tersebut untuk mencegah terjadinya perilaku kekerasan.

\section{KESIMPULAN}

Berdasarkan atas tujuan, hipotesis, hasil penelitian, dan pembahasan yang telah dilakukan maka dapat ditarik kesimpulan dari penelitian yaitu:

1. Diketahui bahwa nilai median dari mengontrol marah sebelum dilakukan strategi pelaksanaan 1 adalah 69,00, standar deviasi 1,444 dan minimum 68, maximum 72

2. Diketahui bahwa nilai rata-rata mengontrol marah sebelum dilakukan strategi pelaksanaan 1 adalah 71,00, standar deviasi 0,808 dan minimum 70, maximum 72. Dari hasil estimasi interval dapat disimpulkan 95\% yang diyakini bahwa rata-rata mengontrol marah adalah Lower 70,77 dan Upper 71,23.

3. Dari hasil uji statistik yang dilakukan, didapatkan bahwa mean rank mengontrol marah sebelum di berikan strategi pelaksanaan 1 adalah 23,23 dan sesudah 10,00. Hasil uji menggunakan wilcoxon di dapatkan nilai $p$ value $=0,000<(0,05)$ yang artinya hipotesis $\mathrm{Ha}$ ada pengaruh terhadap penerapan strategi pelaksanaan 1 sebelum dan sesudah pada klien perilaku kekerasan terhadap mengontrol marah di unit rawat inap Bangau Rumah sakit Ernaldi Bahar Palembang.

\section{SARAN}

Diharapkan dari rumah sakit agar memberikan sosialisasi tentang strategi 
pelaksanaan kepada petugas kesehatan minimal 1 bulan sekali agar strategi pelaksanaan dapat lebih maksimal diterapkan diruangan serta diharapkan perawat selain memberikan strategi pelaksanaan setiap hari juga dapat memberikan semangat atau motivasi agar dapat mempercepat kesembuhan klien.

\section{UCAPAN TERIMA KASIH}

Penulis mengucapkan banyak terima kasih kepada pihak terkait yang telah membantu dan mendukung dalam terlaksananya penelitian ini.

\section{DAFTAR PUSTAKA}

Arikunto, S. 2011. Prosedur Penelitian Suatu Pendekatan praktik. Jakarta: Rineka Cipta.

Dalami, Ermawati. 2009. Asuhan Keperawatan Klien Dengan Gangguan Jiwa. Jakarta - TIM.

Dermawan, D \& Rusdi. 2013. Keperawatan Jiwa; Konsep dzan Kerangka Kerja Asuhan Keperawatan Jiwa. Yogyakarta : Gosyen Publishing.

Elita, dkk. 2011. Presepsi Perawat Tentang Perilaku Kekerasan yang Dilakukan Pasien di Ruang Rawat Inap Rumah Sakit Jiwa Tampan Provinsi Riau. Diakses tanggal 3 Maret 2016 dari ejournal.unri.ac.id./Index.php/JNI/art icle/view/637/630.

Fitria, Nita. 2009. Prinsip Dasar dan aplikasi Penulisan Laporan Pendahuluan dan Strategi Pelaksanaan Tindakan Keperawatan (LP dan SP). Jakarta: Salemba Medika.

Fitria, Nita. 2012. Prinsip Dasar dan aplikasi Penulisan Laporan
Pendahuluan dan Strategi

PelaksanaanTindakan Keperawatan (LP dan SP). Jakarta: Salemba Medika.

Hasniati. Murtiyani. Ilyas (2011). Pengaruh Penerapan Asuhan Keperawatan Pada Klien Perilaku Kekerasan Terhadap Kemampuan Klien Mengontrol Perilaku Kekerasan. Diakses pada tanggal 25 april 2016 dari jurnal

http://library.stikesnh.ac.id/files/disk 1/6/e-

library\%20stikes\%20nani\%20hasanu ddin--hasniatiah-285-1-261360651.pdf.

Hidayat, A. Aziz Alimul. 2007. Pengatar Konsep Dasar Keperawatan. Jakarta. Salemba Medika.

Judith M. Wilkinson (2012). Buku Saku Diagnosa Keperawatan. Jakarta. EGC

Muhith, Abdul ((2015). Pendidikan Keperawatan JIwa Teori dan Aplikasi. Ed. I. Yogyakarta.

Medical Record Rumah Sakit Dr. Ernaldi Bahar Palembang 2016.

Nasir, A \& Muhith, A. 2011. Dasar-Dasar Keperawatan Jiwa. Jakarta. EGC.

Notoatmodjo, Soekidjo. 2012. Metodologi Penelitian Kesehatan. Jakarta: Rineka Cipta.

Nursalam. 2013. Metodologi Penelitian Ilmu Keperawatan. Jakarta. Salemba Medika.

Novitasari, Loren. 2014. Pengaruh Penerapan Strategi Pelaksanaan Pada Klien Halusinasi Terhadap Kemampuan Mengontrol Halusinasi di Ruang Rawat Inap Merpati 1 Rumah Sakit Ernaldi Bahar Palembang Tahun 2014. Skripsi. Palembang, Stikes Perdhaki Charitas.

Suryaningrum, 2013. Hubungan Antara Beban Keluarga Dengan Kemampuan Keluarga Merawat Pasien Perilaku Kekerasan di Poliklinik Rumah Sakit Marzoeki Mahdi Bogor. Diakses pada tanggal 
3 Maret 2016 dari

Jurnal.unimus.ac.id/Index.php/JKJ/ar ticle/view/ 976/1025.

Sya'diyah, H. 2013. Komunikasi

Keperawatan (Communication

Games Aplication). Edisi Pertama.

Yogyakarta: Graha Ilmu.

Videbeck, Sheila. 2008. Buku Ajar

Keperawatan Jiwa. Jakarta: EGC

Videbeck, Sheila. 2012. Buku Ajar

Keperawatan Jiwa. Jakarta: EGC 